\title{
A REPRESENTAÇÃO CULTURAL NAS BRINCADEIRAS INFANTIS DE CRIANÇAS QUE VIVEM NO CAMPO, EM JI-PARANÁ/RO
}

\author{
Helen Maciel da Silval \\ Juracy Machado Pacífico² \\ Leiva Custódio Pereira ${ }^{3}$
}

\section{RESUMO}

A reflexão apresentada neste texto parte de um recorte da pesquisa realizada durante o Mestrado Profissional em Educação Escolar, do Programa de Pósgraduação em Educação Escolar - Mestrado e Doutorado Profissional - PPGEEProf, concluído em 2018. Partiu-se do princípio de que a brincadeira está naturalmente presente na infância. Com isso, buscou-se observar as brincadeiras espontâneas infantis no âmbito escolar e compreender a sua representação cultural, se eram e como eram consideradas nas práticas pedagógicas com crianças de quatro e cinco anos de idade. A pesquisa, de abordagem qualitativa, utilizou para a coleta de dados a observação participante, que foi registrada em diário de bordo e registro fotográfico. A observação foi realizada na turma mista de Pré-Escolar I e II, na Escola Municipal de Educação Infantil e Ensino Fundamental Professor Edson Lopes, localizada na área rural no município de Ji-Paraná/RO. Participaram da pesquisa a professora da turma e 16 crianças entre quatro e cinco anos de idade. Para analisar os dados utilizou-se o referencial teórico da Sociologia da Infância, tendo como principais referências Sarmento e Gouvea (2008), Abramowicz (2011), Faria e Finco (2011) e Corsaro (2011). As contribuições desta área de estudo concebem a criança como sujeito, protagonista da história e dos processos de socialização, apontando a importância dos interesses infantis em questões que diretamente lhes afetam, de que se constituem na cultura, que produz cultura e a influencia. A análise realizada aponta que as brincadeiras infantis são carregadas de sentido e representam parte das vivências cotidianas das crianças e que nelas

\footnotetext{
1 Mestre em Educação escolar. Graduada em pedagogia. Especialista em docência na Educação Infantil. Pesquisadora do Grupo de pesquisa em Educação na Amazônia, Linha de pesquisa Educação infantil: formação docente e práticas pedagógicas. Orcid iD: https://orcid.org/0000-0002-1874-4820. E-mail: helen2maciel@gmail.com

2 Doutora em Educação. Professora Associada da Fundação Universidade Federal de Rondônia e atua no Curso de Licenciatura em Pedagogia, no Programa de Pós-Graduação em Educação Escolar, Mestrado e Doutorado Profissional (PPGEEProf). É líder do Grupo de Pesquisa Multidisciplinar em Educação e Infância (EDUCA), Editora da Revista Educa Revista Multidisciplinar em Educação, e Coordenadora do Laboratório do Brinquedo e da Ludicidade (LABRINTECA) da UNIR. Orcid iD: https://orcid.org/0000-0003-0486-874X. E-mail: juracypacifico@unir.br

3 Graduada em pedagogia e direito. Especialização em Administração e Planejamento para Docentes. Especialização em Tecnologias Educacionais. Especialização em Gestão Pública. Especialização em Psicopedagogia Escolar e Clínica e Mestrado em Educação pela Universidade Federal de Mato Grosso. Professora do Instituto Federal de Educação, Ciência e Tecnologia de Rondônia (IFRO). Orcid iD: https://orcid.org/0000-0002-6904-5616. Email: leivacustodio@gmail.com
} 
estão presentes práticas culturais de dentro e de fora da comunidade. Por outro lado, a pesquisa evidenciou que ainda não foram percebidas pela professora as ricas possibilidades advindas da observação das culturas infantis que podem ser consideradas na prática pedagógica com as crianças. Observa-se a necessidade de formação continuada que oriente o olhar docente para a observação e a escuta das crianças.

Palavras-chave: Infância. Cultura. Identidade.

\title{
CULTURAL REPRESENTATION IN CHILDREN'S PLAY OF CHILDREN LIVING IN THE FIELD, IN JI-PARANÁ/RO
}

\begin{abstract}
The reflection presented in this text is part of a section of the research carried out during the Professional Master's degree in School Education, of the Graduate Program in School Education - Master and Professional Doctorate - PPGEEProf, completed in 2018. It was assumed that play is naturally present in childhood. Thus, we sought to observe the spontaneous play of children in the school environment and understand their cultural representation, whether they were and how they were considered in pedagogical practices with children aged four and five years. The research, with a qualitative approach, used participant observation for data collection, which was recorded in a logbook and photographic record. The observation was carried out in the mixed class of Preschool I and II, at the Municipal School of Early Childhood Education and Elementary School Professor Edson Lopes, located in the rural area in the municipality of Ji-Paraná/RO. The study was the class teacher and 16 children between four and five years of age. To analyze the data, we used the theoretical framework of Sociology of Childhood, having as main references Sarmento and Gouvea (2008), Abramowicz (2011), Faria and Finco (2011) and Corsaro (2011). The contributions of this area of study conceive the child as a subject, protagonist of history and socialization processes, pointing out the importance of children's interests in issues that directly affect them, that constitute culture, which produces culture and influence. The analysis shows that children's games are loaded with meaning and represent part of the children's daily experiences and that cultural practices are present inside and outside the community. On the other hand, the research showed that the teacher has not yet perceived the rich possibilities of observing children's cultures that can be considered in pedagogical practice with children. There is a need for continued training that guides the teaching gaze to the observation and listening of children.
\end{abstract}

Keywords: Childhood. Culture. Identity.

\section{REPRESENTACIÓN CULTURAL EN EL JUEGO INFANTIL DE LOS NIÑOS QUE VIVEN EN EL CAMPO, EN JI-PARANÁ/RO}

\section{RESUMEN}

La reflexión presentada en este texto forma parte de un apartado de la investigación realizada durante el Máster Profesional en Educación Escolar, del 
Programa de Postgrado en Educación Escolar - Máster y Doctorado Profesional PPGEE Profesional, finalizado en 2018. Se asumió que el juego está naturalmente presente en la infancia. Así, se buscó observar el juego espontáneo de los niños en el ambiente escolar y comprender su representación cultural, si lo fueron y cómo fueron considerados en prácticas pedagógicas con niños de cuatro y cinco años. La investigación, con un enfoque cualitativo, utilizó la observación participante para la recolección de datos, que fue registrada en un cuaderno de bitácora y registro fotográfico. La observación fue realizada en la clase mixta de Preescolar I y II, en la Escuela Municipal de Educación Infantil y Escuela Primaria Profesor Edson Lopes, ubicada en la zona rural del municipio de Ji-Paraná/RO. El estudio fue el profesor de la clase y 16 niños entre cuatro y cinco años de edad. Para analizar los datos, se utilizó el marco teórico de sociología de la infancia, teniendo como referencias principales Sarmento y Gouvea (2008), Abramowicz (2011), Faria y Finco (2011) y Corsaro (2011). Los aportes de esta área de estudio conciben al niño como un sujeto, protagonista de la historia y de los procesos de socialización, señalando la importancia de los intereses de los niños en temas que les afectan directamente, que constituyen cultura, que produce cultura e influencia. El análisis muestra que los juegos infantiles están cargados de significado y representan parte de las experiencias cotidianas de los niños y que las prácticas culturales están presentes dentro y fuera de la comunidad. Por otro lado, la investigación mostró que el maestro aún no ha percibido las ricas posibilidades de observar las culturas de los niños que pueden ser consideradas en la práctica pedagógica con los niños. Es necesaria una formación continua que guíe la mirada didáctica hacia la observación y la escucha de los niños.

Palabras clave: Niñez. Cultura. Identidad.

\section{INTRODUÇÃO}

Rondônia é um estado vasto e composto por pessoas que vivem em espaços urbanos, mas também por uma diversidade de pessoas que vivem em espaços não urbanos. A Resolução CNE/CEB n 1/2002, que estabelece as Diretrizes Operacionais para o Campo, reconhece como população do campo 4 os agricultores familiares, extrativistas, pescadores artesanais, ribeirinhos, assentados e acampados da reforma agrária, quilombolas, caiçaras e povos da floresta. O Decreto $n^{\circ} 7.352 / 2010$, que dispõe sobre a política de Educação do Campo, e o Programa Nacional de Educação na Reforma Agrária - PRONERA, acrescentam a essa população os trabalhadores assalariados, os caboclos e outros que produzam suas

\footnotetext{
4 População do campo são as pessoas que residem em espaços não urbanos. O debate acadêmico tem problematizado sobre quem são os sujeitos do campo como, por exemplo, os povos da floresta. Povos da floresta, expressão de Chico Mendes e assim autointitulados na região do Médio Solimões, na Amazônia, ou populações tradicionais, assim denominadas pelas Ciências Sociais (SANTILLI, 2005, p. 124-125).
}

Revista Exitus, Santarém/PA, Vol. 12, p. 01-21, e022002, 2022. 
condições materiais de existência a partir do trabalho no meio rural.

Em Ji-Paraná/RO estão presentes muitas dessas representações de infâncias de modo que localizamos agricultores, pescadores, assentados e acampados da reforma agrária e povos da floresta. No entanto, nosso recorte nesta pesquisa volta-se para os agricultores, produtores rurais e assalariados que têm crianças matriculadas em uma escola do campo.

A compreensão das condições materiais de existência dos sujeitos que compõem uma turma de pré-escola foi possível a partir da análise que realizamos dos dados de um questionário sociocultural que a professora enviou aos pais. Este demonstrou que a atividade econômica desempenhada pelas famílias varia entre produtores rurais, criadores de gado e funcionários de fazendas e sítios. Portanto, é nestes espaços rurais que as crianças estabelecem suas relações sociais, seus valores humanos, suas subjetividades e identidades, seu jeito de viver em sociedade.

A discussão sobre Educação Infantil no/do campo é recente no país, estão envolvidas concepções diversas de infâncias, de educação e de campo que acendem tensões e conflitos confirmando as contradições da sociedade e as necessidades de analisar sua complexidade. Fica evidente que:

O importante aqui é ter a consciência de que cada um desses posicionamentos revela possibilidades ou restrições à inclusão do tema da criança e da infância como correlacionado ao próprio conceito de campo. É apenas a partir da concepção de campo como lugar de vida que é possível articular as duas temáticas infâncias e campo (SILVA; SILVA; MARTINS, 2013, p. 16, grifo nosso).

Partindo da premissa de que compreendemos o campo como o lugar de vida das crianças é que recorremos à Sociologia da Infância para buscar elementos teóricos metodológicos para compreender as especificidades das crianças que vivem no campo, aqui representadas pelos filhos de produtores rurais, assalariados e criadores de gado de corte ou leiteiro. Trataremos da infância do campo, independentemente de suas condições materiais, ou seja, não somente da infância pobre, mas da infância escolarizada. 


\section{AS CRIANÇAS DO CAMPO E A CULTURA INFANTIL. UM DIÁLOGO COM A SOCIOLOGIA DA INFÂNCIA}

A Educação Infantil é uma etapa muito importante para o desenvolvimento integral da criança. Falar dessa etapa da educação básica é pensar em espaço institucional, educacional, um espaço coletivo importante para os processos de socialização, aprendizagem e desenvolvimento das crianças. Este sujeito, a criança, com direito à educação escolar, é compreendida "Sujeito histórico e de direitos que, nas interações, relações e práticas cotidianas que vivencia, constrói sua identidade pessoal e coletiva [...]", e, principalmente pela condição e entendimento que temos, a de que é sujeito e não objeto ou ser inferior ou um vir a ser coloca-se em condições de interagir com outros seres humanos, sejam estes adultos ou também crianças, e não humanos, e com eles "[...] brinca, imagina, fantasia, deseja, aprende, observa, experimenta, narra, questiona e constrói sentidos sobre a natureza e a sociedade, produzindo cultura" (BRASIL, 2009, Art. 4\%).

Silva, Pasuch e Silva (2012) nos remetem ao direito que reconhece a importância da creche e a pré-escola para os processos de socialização complementares aos da família, em ambiente coletivo e especialmente organizado para educá-las, em que são potencializadas as interações entre crianças de diferentes e da mesma idade, e que Ihes permitem a vivência de experiências diversificadas nos processos de conhecimento do mundo, de seu entorno e de si mesmas.

Pensando nessa criança contemporânea é necessário que a escola do campo observe e considere os seus interesses, sua cultura, sua identidade enquanto moradora de espaços rurais, sua ligação com a natureza e com o entorno.

É necessário compreender que a criança aprende brincando e interagindo, utilizando a imaginação, a fantasia, que precisa de tempo para observar os objetos de seu entorno, precisa vivenciar, experimentar, fazer suas narrativas e questionamentos e neste movimento constrói sentidos sobre 
si, sobre os outros, sobre as coisas e produz cultura.

É importante conhecer e demarcar as especificidades da produção cultural na Infância. Suas manifestações culturais estão presentes na forma como se comunicam com adultos e crianças, nas mais variadas linguagens, nas brincadeiras, nos desenhos, nos jogos simbólicos, entre outros. A esse respeito, Coutinho afirma que:

As manifestações infantis são provenientes de uma cultura própria das crianças. Suas expressões, nas variadas linguagens, decorrem da relação com a cultura que a cerca, ou seja, com os bens culturais que a sociedade disponibiliza para elas [...]. A representação de cenas do cotidiano, pelas crianças expressando conhecimentos produzidos socialmente são reelaborados pelas mesmas em suas vivências, elas recriam situações já presenciada e criam, assim uma cultura infantil (COUTINHO, 2002, p. 99).

Sarmento (2004) afirma a ludicidade como traço fundamental das crianças, apontando que o brincar é muito do que as crianças fazem de mais sério, que por meio da brincadeira revela-se um dos traços da cultura infantil.

Com efeito, a natureza interactiva do brincar das crianças constituise como um dos primeiros elementos fundacionais das culturas da infância. O brincar é a condição da aprendizagem e, desde logo, da aprendizagem da sociabilidade. Não espanta, por isso, que o brinquedo acompanhe as crianças nas diversas fases da vida da construção das suas relações sociais. $O$ brinquedo e o brincar são também fator fundamental na recriação do mundo e na produção das fantasias infantis (SARMENTO, 2004, p. 26).

As interações e as brincadeiras se constituem como eixo estruturante do fazer pedagógico na Educação Infantil, pois é por meio delas que a criança pequena aprende a conhecer a si mesmo, o outro e o mundo.

$\mathrm{Na}$ escola do campo está presente uma diversidade de crianças, o que nos remete a uma diversidade de infâncias, cada uma delas traz uma história de vida, um jeito de ser criança e viver em comunidade. São marcadas pelos atravessamentos culturais como o gênero, a raça, etnia, a classe social, a globalização, entre outros.

A cultura não deve ser concebida como um saber a ser ensinado pela escola, mas como o contexto da vida cotidiana e ao ser inserido na escola 
estes elementos culturais contribuem para que a escola faça sentido para a criança, dando-lhe o sentimento de pertença.

Compreendemos que valorizar a cultura do campo significa criar vínculo com a comunidade e gerar um sentimento de pertencimento ao lugar e as pessoas, fortalecendo a identidade positiva de si e do outro.

Buscamos compreender o conceito de cultura da infância em Corsaro (2011, p. 19), para quem as crianças, assim como os adultos, são participantes ativos na construção social da infância e na reprodução interpretativa de sua cultura compartilhada. Neste sentido, a socialização é um processo de apropriação, reinvenção e reprodução (CORSARO, 201 1, p. 31). Nessa perspectiva, as crianças observam, reinventam, negociam, experimentam, compartilham e criam cultura com seus pares e com adultos, demonstram a maneira como veem e concebem o mundo.

Hall (2006, p. 13) afirma que a identidade torna-se uma "celebração móvel" formada e transformada continuamente em relação às formas pelas quais somos representados ou interpelados nos sistemas culturais que nos rodeiam. Ou seja, a identidade das crianças que vivem no campo é interpelada e se modifica na medida de suas experiências cotidianas, com a convivência com diferentes sujeitos, com o conhecimento, informações e o acesso aos bens culturais.

A identidade das infâncias do campo é entrecruzada pela cultura local e global, pois a integração espacial das crianças extrapola as fronteiras da cidade, da vizinhança e da escola, porque a televisão, o rádio os aparelhos celulares, a internet principalmente, as conectam a múltiplos outros lugares (FELIPE, 2013, p. 31). O universo cultural das crianças no campo traz as marcas da globalização, elas são interlocutoras de uma cultura apresentada fortemente pelos meios midiáticos, que são representados em suas falas, desenhos, brinquedos e brincadeiras.

Desta forma, não se concebe mais a representação do camponês como um sujeito rude, atrasado ou inferior ao homem da cidade, pelo contrário. Neste sentido, a escola tem um papel fundamental que é de valorizar a cultura local como forma de reconhecer sua identidade, seu 
modo de vida, suas atividades laborais como fundamentais para a composição de uma sociedade plural.

Assim, na condição de adultos temos um papel importante para que interações sejam possíveis. Trata-se de ouvir as crianças. Sobre essa questão, Edwards (2016, p. 156) diz que escutar significa "estar plenamente atento às crianças e, ao mesmo tempo, assumir a responsabilidade por registrar e documentar o que é observado, significa buscar seguir e entrar na aprendizagem enquanto ela ocorre". Para Rinaldi (2016, p. 236) "a escuta precisa ser aberta e sensível à necessidade de ouvir e ser ouvido com e à necessidade de escutar com todos os nossos sentidos, não só com os ouvidos". Ou seja, escutar pressupõe reconhecer as diversas linguagens que as crianças utilizam para se comunicar e se expressar.

Com o propósito de garantir a escuta das crianças em ambientes coletivos, a Sociologia da Infância convoca a Educação Infantil a fazer algumas inversões em sua prática pedagógica, de maneira que, ao compreender a criança como sujeito de direito, protagonista e ator social, seja levada a descentralizar a ação do adulto, ou seja, o professor que sempre decidiu, escolheu, elegeu as atividades, passa a observar as crianças, ouvir e considerar seus interesses e propor estudos e pesquisas para ampliar o conhecimento produzido pela humanidade. Ao docente cabe uma escuta pedagógica.

É importante a compreensão de que toda prática pedagógica é orientada por um currículo. A este respeito Sacristán (1999, p. 15) afirma que o currículo supõe a concretização dos fins sociais e culturais, de socialização, a que se atribui a educação escolarizada. É, também, reflexo de um modelo ideológico e os professores o modelam por meio de suas práticas.

As práticas pedagógicas supõem intencionalidade, valor formativo, potencialidades para a ampliação do conhecimento de mundo das crianças pequenas, sendo necessário considerar a diversidade de infâncias presente na comunidade rural ao pensar a organização do trabalho pedagógico. É importante destacar que: 
[...] na organização do espaço a diversidade cultural deve ser considerada para que o direito à vida infantil, ou seja, à infância e a melhores condições de vida seja garantido à todas as crianças (pobres, ricas, brancas, negras, indígenas, meninos, meninas, estrangeiras, brasileiras, portadoras de necessidades especiais, etc.) (PACÍFICO, 2010, p. 206).

Todas as crianças devem ser acolhidas pela escola e o modo como o professor permite a organização das representações das diversidades culturais da comunidade no espaço escolar, propõe a vivência de experiências, se relaciona com as crianças e organiza os tempos e os espaços revelam como vem modelando o currículo da Educação Infantil e as suas concepções de infâncias.

Considerar a criança como sujeito é levar em conta, nas relações que com ela estabelecemos, que ela tem desejos, ideias, opiniões, capacidade de decidir, de criar, de inventar, que se manifestam, desde cedo, nos seus movimentos, no seu olhar, nas suas vocalizações, na sua fala (SALLES; FARIA, 2012, p. 56).

Compreendemos que a organização do trabalho pedagógico com as crianças que vivem no campo deve considerar o contexto cultural, reconhecer o protagonismo infantil, enxergá-las como produtoras ativas de cultura para planejar as práticas pedagógicas.

Desta forma, a escola é considerada espaço de pesquisa, experimentação observação para construção de saberes no âmbito da Educação Infantil do campo, concordando com o entendimento de que o espaço escolar como fonte de pesquisa permite aos profissionais a reflexão e produção de conhecimentos pautados em suas ações pedagógicas (SILVA; MACHADO; PACÍFICO, 2018, p. 117).

Embasamo-nos nesse referencial teórico que nos apresenta uma concepção de criança potente, participativa, imaginativa, investigativa e que é produtora de cultura; que considera a brincadeira uma cultura infantil e que nela se revela muito de sua vida; que olha para a etapa da Educação Infantil como fundamental para o desenvolvimento integral das crianças, e com isso fomos ao campo para levantar dados de como os elementos culturais representados nas brincadeiras são consideradas na prática 
pedagógica, no contexto das infâncias do campo.

Além disso, também fomos ao campo da pesquisa com a ideia préconcebida de que a prática pedagógica revela as concepções da escola e de professores relacionados à educação de crianças pequenas. "O modo como organizamos os materiais e móveis e a forma como crianças e adultos ocupam esse espaço e como interagem com eles são reveladores de uma concepção pedagógica" (HORN, 2004, p. 15). Nessa direção, observamos alguns espaços da escola, tais como os espaços externos à sala de referência a sala de aula da turma da pré-escola, sua composição e as brincadeiras espontâneas realizadas pelas crianças a fim de compreender os elementos culturais que emergem ou emergiam do/no ambiente escolar.

\section{MÉTODO DA PESQUISA}

A pesquisa, de abordagem qualitativa, utilizou a observação participante para a coleta de dados. Foram realizados registros fotográficos e registros em diário de bordo. A observação foi realizada na turma mista de pré-escola I e II, na Escola Municipal de Educação Infantil e Ensino Fundamental Professor Edson Lopes, localizada na área rural no município de Ji-Paraná/RO.

Participaram da pesquisa a professora da turma e dezesseis (16) crianças com idade entre quatro e cinco anos.

Os dados foram analisados tendo o referencial teórico da Sociologia da Infância como basilar, sendo que as principais referências foram Sarmento e Gouvea (2008), Abramowicz (2011), Faria e Finco (2011) e Corsaro (2011).

\section{A OBSERVAÇÃO: O QUE EMERGE DAS CRIANÇAS?}

Observar crianças não é algo simples, pois requer exatamente essa capacidade de escuta. No entanto, como somos seres inacabados e com a capacidade de aprender sempre, fomos em busca de cenas do cotidiano que nos fizessem ver as infâncias e suas idiossincrasias.

Realizamos vinte (20) horas de observação na turma mista de pré- 
escolar I e II, acompanhamos, durante uma semana, toda a rotina da turma para compreender como organiza-se a prática docente, considerando a cultura e a identidade de crianças moradoras do campo. Faremos uma breve descrição do período de observação, destacando as brincadeiras espontâneas infantis observadas, que serão o mote da análise deste texto.

A professora que atuava na turma mista da Educação Infantil, composta por crianças de Pré I e Pré II, possui graduação em pedagogia e especialização. No entanto, seu maior tempo de atuação foi em turmas do ensino fundamental.

A sala de referência das crianças fica localizada no pátio, próximo ao bloco administrativo. Ela era ampla, iluminada e arejada. A mobília era composta por um bebedouro, dois armários e mesas com cadeiras individuais, adequadas à estatura das crianças.

As mesas e cadeiras eram arranjadas em um único grupo, permitindo um amplo espaço de circulação dentro da sala de referência. No piso havia um tapete grande de EVA que ficava, de forma confortável, disposto em um canto da sala para a realização de rodas de conversas, rodas de leitura e brincadeiras.

As crianças gostavam de aproveitar o tempo de espera para brincar no tapete com blocos lógicos e com outros brinquedos disponíveis na sala. Neste momento, põem em jogo a imaginação e a concentração nos jogos de construção e representação.

As paredes da sala de referência apresentam pinturas envelhecidas e desgastadas. As marcas do tempo e de usos são visíveis, como marcas de colagem e escritas com pincel atômico deixado por turmas anteriores, buracos e outros aspectos que, ao nosso ver, não deixam o espaço físico com aparência de que está sendo cuidado. Em alguns pontos, a cerâmica da parede está se soltando. Porém, para compor a ambiência pedagógica, a professora cobriu com tecido de TNT pontos em que falta a cerâmica e conseguiu dar uma boa ambiência pedagógica ao local.

O que chama atenção é que apesar dos esforços da professora em dispor de muitos recursos como alfabeto, calendário, lista de nomes, entre 
outros, a sala de aula estava com ausência de produção infantil. As marcas das crianças, seus desenhos, suas escritas ou registros não apareciam na composição do espaço da sala de referência. Carvalho, Klisys e Augusto (2006, p. 43) apontam que "a instituição de Educação Infantil é um lugar de convergências entre $O$ universo do conhecimento e $O$ mundo da subjetividade humana". Consequentemente, é um espaço rico para imaginação, criação e representação infantil.

Outro aspecto observado é que não apareciam elementos que representassem as características de moradores de área rural e seu universo cultural. Benjamim e Caldart (2000) defendem a necessidade de a escola do campo considerar as características culturais dos sujeitos do campo fortalecendo e reafirmando sua identidade. Além da cultura local é importante o entendimento que,

A cultura deve estar intrinsecamente relacionada com a maneira pela qual a criança conduz e constrói a sua vida. Com as oportunidades que the são oferecidas de conhecer a produção humana, mais rica será sua maneira de se expressar, sentir e construir conhecimento (CARVALHO; KLISYS; AUGUSTO, 2006, p.43).

Os elementos culturais vindos da concretude de suas vidas diárias e com os quais as crianças se identificam fortalecem sua identidade enquanto moradores da área rural. Pactuamos do entendimento de que ao conhecer a própria história e valorizar a identidade pessoal como ponto de partida para conhecer o mundo, quanto mais a criança tiver oportunidade de conhecer a produção humana, mais irá aprender e se desenvolver.

Em relação aos materiais didático-pedagógicos, observou-se que na sala de aula tem livros infantis de boa qualidade, brinquedos, como blocos lógicos, lego, bolas, bambolês e alguns jogos pedagógicos para trabalhar o nome das crianças, estes construídos pela professora. A escola recebeu um playground em polietileno que naquele período estava desmontado. Era evidente a ausência da representação da cultura local nos brinquedos, materiais e nos espaços internos e externos à sala de aula de referência. É importante o reconhecimento que, 
Na Educação Infantil das crianças do campo, a creche/pré-escola pode assumir diversas significações, desde um espaço de descobertas sobre o próprio mundo, por meio das brincadeiras e experimentação de sensações, atreladas ao conhecimento produzido pela humanidade e sua comunidade, até como um lugar de submissão da infância aos processos escolarizantes e externos à realidade rural, negando-a como espaço de vida (SILVA; PASUCH; SILVA, 2012, p. 155).

Nesse sentido, é importante que o professor observe a comunidade, as crianças e o que elas trazem de elementos para fazer as escolhas de materiais, de brinquedos e de espaços para a experimentação a fim de romper com uma identidade de Educação Infantil no Campo meramente escolarizante e urbanoide.

Apresentaremos a seguir algumas cenas onde as crianças brincam com seus pares e dialogam entre si. Por meio da observação destas situações, em que as crianças representam sua vida cotidiana, percebe-se os elementos da cultura local que delas emergem.

Cena 1: A professora parece ter clareza da importância da ludicidade na aprendizagem e no desenvolvimento infantil e propõe muitas situações de brincadeiras. Nesta, ela estava trabalhando uma atividade que consistia em contar as figuras de casas. Em seguida, entrega uma massinha de modelar para as crianças e orienta para modelar a sua casa. Elas demonstram interesse pela atividade, gostam de brincar e modelar com a massinha. H. C diz: "Tenho duas casas: uma minha e o galinheiro, onde as galinhas moram". B. L. diz: "Tenho um boi do chifre bem grande e galinha também, mas elas não têm casa". H.C. diz: "A galinha chocou um monte de pintinhos". Nesse diálogo, uma das crianças traz um elemento novo, o "galinheiro", e o entendimento de que os animais têm seus espaços organizados de modo diferente.

Refletimos como essas falas das crianças poderiam ser consideradas na prática docente, já que ao falar do galinheiro as crianças estão falando de suas vivências cotidianas, da concretude de suas vidas, de suas incertezas e de suas curiosidades. A partir dessa Cena observada, colocamo-nos a pensar: que novas pesquisas e aprendizagens poderiam surgir a partir da temática galinheiro? Quem/quais seriam as pessoas da comunidade que teriam galinheiro e se disporiam a conversar com as crianças sobre suas dúvidas e (in)certezas a respeito das galinhas e do 
galinheiro? Seria interessante um canto temático para explorar e registrar os conhecimentos a respeito de tal temática? Do lugar de quem observava pensamos que essas várias questões poderiam ser ponto de partida para pesquisas e investigações realizadas pelas/com as crianças e, a partir disso, se teria a ampliação dos conhecimentos e abertura para muitos outros conhecimentos.

As DCNEl pautam que é nas interações e vivenciando as práticas cotidianas que a criança constrói sua identidade pessoal e coletiva, demonstrando aqui a importância de se valorizar na prática pedagógica da escola do campo, o cotidiano das crianças.

Sobre essa questão já contribuíram as autoras do livro Educação Infantil do Campo, quando pautam a importância de que as práticas pedagógicas devem estar vinculadas com a concretude da vida das crianças.

[...] colocar no centro da ação pedagógica a concretude da vida da criança do campo: seus espaços de convívio, seus ritmos de viver o tempo, sua participação na produção coletiva de seus familiares e de suas comunidades, seus brinquedos e brincadeiras organicamente vinculados aos modos culturais de existir (SILVA; PASUCH; SILVA, 2012, p. 36).

Considerar a concretude da vida das crianças do campo é pensar que elas vivem numa organização familiar e comunitária, com um jeito próprio de organização de sua participação nas atividades cotidianas. Que por viverem em contato com a natureza trazem consigo experiências diversas e o desafio da escola é compreender esse modo de vida da criança do campo para que possa considerá-las em todas as suas especificidades.

Cena 2: As crianças recebem blocos de encaixe de plástico e começam a brincar e, pelo que observávamos, estavam a imaginar e criar. Nessa brincadeira observamos que o objetivo da professora era oportunizar a imaginação e as brincadeira de construção. "Olha professora, fiz uma máquina de passar veneno", diz uma criança. Outra diz: "Eu fiz um ônibus". A professora pergunta a outra criança: "E você, o que fez?" "Eu fiz uma cobra gigante". As crianças se divertem com seus brinquedos inventados e partilham uns com os outros. 
As crianças representaram objetos e animais diversos. Destacamos a máquina de passar veneno, que é um objeto utilizado pelos adultos no trabalho; o ônibus, que é o meio de transporte utilizado por todos para chegar até a escola; e, a cobra, um animal presente no meio rural e muitas vezes as crianças a temem. As representações demonstram o conhecimento a respeito do trabalho desenvolvido pelos familiares, conhecimentos sobre a natureza, a representação da vida cotidiana e seu modo de viver no campo. Em função de um currículo, às vezes prescritivo e fechado, ou por ausência de orientação e formação por parte da escola, muitas oportunidades de aprendizagens ricas de significados são desconsideradas.

Em relação às Propostas Pedagógicas para as infâncias do campo, as Diretrizes Curriculares Nacionais para a Educação Infantil preconizam a importância de "[...] valorizar e evidenciar os saberes e o papel dessas populações na produção de conhecimentos sobre o mundo e sobre o ambiente natural" (BRASIL, 2009. p. 24).

$\mathrm{Na}$ construção dos brinquedos ficou evidente a representação das vivências cotidianas das crianças no âmbito familiar. O que nos chamou a atenção foi a representação da máquina de veneno e a naturalidade do diálogo sobre essa representação, demonstrando que a prática de aplicação de veneno é uma atividade rotineira e considerada normal, já que está presente, inclusive, nas brincadeiras infantis. Tal aspecto talvez pudesse ser apontado como uma temática que poderia ser problematizada pela professora com o grupo de crianças.

Colocamo-nos a pensar sobre a possibilidade de provocar uma pesquisa sobre essa problemática com as crianças e pensamos em algumas questões que poderiam ser motivo de investigação: seria válido o questionamento sobre o que acontece na natureza com essa prática? É benéfico? Onde podemos encontrar respostas? O que as crianças pensam e conhecem sobre essa prática? Que outras possibilidades de estudos poderiam emergir a partir da pesquisa sobre a prática de passar veneno e sobre a responsabilidade com o meio ambiente? Existem outras maneiras menos prejudiciais para o controle de pragas? Onde buscar novas 
informações? A atenção às manifestações das crianças demonstra que se o docente estiver atento, observando e ouvindo as crianças com a possibilidade de colocá-las no centro do trabalho pedagógico, as possíveis interações podem ser ricas e potentes.

Cena 3: um grupo de crianças inicia uma brincadeira no tapete. Envolvia meninos e meninas que utilizam apenas o corpo para realizar a brincadeira, a qual consistia em imitar uma montaria. Sorriam enquanto gritavam: "Pula boi"! As meninas pegavam pelos pés e mãos o menino que representava o boi, e dizem: "O boi morreu"! "Morre boi"! As crianças realizaram essa brincadeira em um momento de espera, em que a professora precisou ausentar-se da sala para acompanhar outra criança até o banheiro. Representaram papéis que vivenciam no dia a dia.

$\mathrm{Na}$ brincadeira com o menino na condição de boi, as crianças representaram um papel social ao simular uma montaria e o abate de um bovino. Encenaram o lugar onde moram, o trabalho dos pais e a sua história. Nestas representatividades infantis compreendemos as marcas culturais que confirmam as ideias dos pesquisadores da Sociologia da Infância, como é o caso de Sarmento, que afirma:

As crianças incorporam, interpretam e reconstroem continuamente informações culturais, constituídas por valores, normas sociais, ideias crenças e representações sociais, frequentemente expressas sob a forma de histórias e narrativas, lendas, imagens, jogos, brinquedos e brincadeiras e outros artefatos culturais. A construção dos universos simbólicos das crianças é realizada na interacção entre crianças e adultos e entre crianças e crianças (SARMENTO, 2007, p. 36).

Compreendemos que à escola cabe criar contextos instigantes para as mais variadas formas de comunicação infantil e valorizar as histórias de vida das crianças para que construam uma imagem positiva de si mesmas.

As brincadeiras encenadas pelas crianças são comuns no espaço educacional e são percebidas no recreio e em outros momentos de espera onde haja qualquer possibilidade de interação da criança com outras pessoas, outros seres vivos ou objetos e brinquedos.

A partir das Cenas observadas e descritas neste texto, refletimos com a professora possibilidades de trazer para as vivências e experiências das 
crianças os objetos, materiais e artefatos utilizados no campo com o objetivo de compor os espaços e as brincadeiras das crianças e possibilitar a vivência de práticas sociais.

$\mathrm{Na}$ instituição pesquisada, predominam as atividades escolarizantes, fruto de um currículo prescrito e ultrapassado, organizado geralmente em formato de listas de conteúdos a serem desenvolvidos. Para Sacristán (1999, p. 111), "listas de conteúdo, supõe a definição das aprendizagens exigidas a todos os estudantes e, portanto, é homogêneo para todas as escolas. Implica uma normalização cultural". Tal afirmação se dá pela observação e análise das propostas de atividades realizadas pelas crianças durante, onde verificamos que foram vivenciados poucos momentos de brincadeiras e muitas propostas voltadas para as preocupações com conteúdo prescrito.

Souza (2000, p. 102) chama a atenção para o fato de que "a criança é um sujeito em processo de desenvolvimento, histórica e culturalmente situada, com direitos, características e necessidades próprias". Ao observar as brincadeiras das crianças ficaram evidentes as marcas de seus modos de viver, suas representações e suas culturas e identidades. Indica que é necessário a ressignificação das práticas pedagógicas para que estas considerem as infâncias do campo.

\section{DISCUSSÕES E CONSIDERAÇÕES FINAIS}

Com o entendimento de que a criança é um sujeito histórico e de direito e que deve ser considerada, compreendemos que "a fala da criança é uma inversão nos processos de subalternização, é um movimento político" (ABRAMOWICZ, 2011. p. 24).

Ao concluir o trabalho pensamos em como possibilitar a autonomia, a participação e o protagonismo infantil se a escola ainda não construiu a cultura da escuta às crianças. Desde pequenas as crianças precisam ser reconhecidas pela escola como sujeitos, isso implica reconhecer suas capacidades de interação, de criação, de comunicação e que a autonomia é um processo de construção que se cultiva com a própria autonomia. Cada criança traz consigo um sujeito potente que se desenvolve 
e aprende nas relações e interações que vivencia no dia a dia.

Propõe-se as escutas dos bebês e das crianças pequenas, considerando-as como sujeitos que vivem em momentos históricos concretos e desempenham ações socialmente significativas. Cada vez mais se acredita que as crianças podem nos dizer, mesmo as crianças pequenas e à sua maneira, o que pensam de suas infâncias e como gostariam que fosse suas experiências na Educação Infantil (SILVIA; PASUCH; SILVA, 2012, p. 98).

O exposto acima aponta que a Educação Infantil, como primeira etapa da Educação Básica, deve ouvir as crianças, considerar o que pensam e seus interesses na prática pedagógica, compreendendo que esta é uma ação política importante para professores e crianças. O ato da escuta sensível pode ser base para interessantes projetos integradores entre escola, comunidade e família.

A escola precisa compreender que tudo na Educação Infantil deve ser educativo e deve ter também uma intencionalidade. Neste sentido, a escola é como uma sinfonia onde espaços, materiais, crianças e adultos interagem de forma planejada para provocar nas crianças curiosidades e encantamentos, diálogos e imaginação para que neste movimento as crianças tenham suas marcas infantis reconhecidas. Dessa forma é possível olhar para as crianças como atores sociais e produtores de cultura, valorizando suas produções, suas formas de ver, entender e se relacionar com o mundo. O olhar e as ações das crianças precisam ganhar espaço e visibilidade na escola se considerarmos que a escola é para a criança.

Compreendemos que a experiência da docente no ensino fundamental serve de referência para muitas de suas práticas, mas entendemos a necessidade de um processo formativo que reflita as concepções de criança, de educação infantil e das interações e brincadeiras como eixos estruturantes das propostas e das práticas pedagógicas. As gestões públicas de uma maneira geral também tratam a infância e, principalmente, a Educação Infantil, como uma etapa de ensino menos importante que as demais. Isso reflete nas políticas de formação inicial e continuada dos professores e na forma como os profissionais são 
selecionados para atuação. Muitos são lotados em turmas de Pré-Escola, sem compreender minimamente os processos de aprendizagem e desenvolvimento infantil e as especificidades dessa etapa.

Sabemos que para uma criança pequena tudo é experimento. Situações que podem irritar um adulto, como jogar e brincar com o prato de comida, para a criança é uma brincadeira, e ao vivenciar essa prática social ela se apropria, aprende e se desenvolve iniciando um processo de construção de noções sobre as propriedades da realidade. Por essa razão é que as vivências cotidianas devem ser consideradas na organização do trabalho com as crianças da educação infantil.

A brincadeira é uma marca da cultura infantil, é por meio dela que as crianças enxergam e representam o mundo, expressam sentimentos, resolvem situações conflitantes, criam, recriam e imaginam, e nestas experiências, no ato de brincar, aprendem e se desenvolvem. Através das brincadeiras e a partir dos múltiplos sentimentos que afloram no brincar, a criança faz a sua leitura do mundo.

O desafio neste momento para a docente é desenvolver a habilidade da observação, da escuta atenta e, sobretudo, considerar essas informações para selecionar os materiais, os brinquedos e para propor situações em que as crianças, ao estarem no ambiente escolar, tenham o sentimento de pertencimento tanto para com a escola como para com o campo.

\section{REFERÊNCIAS}

ABRAMOWICZ, A. A Pesquisa com crianças em Infâncias e a Sociologia da Infância. In.: FARIA, A. L. G.; FINCO, D. Sociologia da Infância no Brasil.

Campinas: Autores Associado, 2011 . Coleção Polêmicas do nosso tempo.

BENJAMIN, C.; CALDART, R. S. Projeto popular e escolas do campo. Brasília: Articulação Nacional Por uma Educação Básica do campo, 2000. (Coleção Por uma Educação Básica do campo v. 3).

BRASIL. Conselho Nacional de Educação. Resolução CNE/CEB n 5/2009. Diretrizes Curriculares Nacionais para a Educação Infantil. Brasília, DF: Diário Oficial da União, 18 dez. 2009. 
BRASIL. Resolução CNE/CEB n 1, de 03 de abril de 2002. Institui as Diretrizes Operacionais para a Educação Básica nas Escolas do Campo. Diário Oficial da União, Brasília, DF seção 1, p. 32.

BRASIL. Decreto $N^{\circ}$ 7.352, de 4 de novembro de 2010. Dispõe sobre a política de educação do campo e o Programa Nacional de Educação na Reforma Agrária - PRONERA. Diário Oficial da União - Seção 1 - 5/11/2010.

CARVALHO, S. P.; KLISYS, A.; AUGUSTO, S. (Org.). Bem Vindo Mundo! Crianças, cultura e formação de educadores. São Paulo: Petrópolis, 2006. 205 p.

CORSARO, W. A. Sociologia da Infância. Trad. De Lia Gabriele Regius Reis. Porto Alegre: Artmed, 2011.

COUTINHO, Â. S. As crianças no interior da creche: a educação e o cuidado nos momentos de sono, higiene e alimentação. Florianópolis, SC. Dissertação de mestrado, CED/UFSC: 2002.

EDWARDS, C. Professor e Aprendiz: Parceiro e Guia. O Papel do Professor. In.: EDWARDS, C.; GANDINI, L.; FORMAN, G. As Cem Linguagens da criança: A experiência de Reggio Emília em transformação. Porto Alegre: Penso, 2016. V. 2, 399 p.

FELIPE, E. S. Infâncias de Assentamento e suas temporalidades históricas. In.: FELIPE, E. S. Infâncias do Campo. 4. ed. Belo Horizonte: Autêntica, 2013. Cap. 1. p. $25-40$.

HALL, S. A identidade cultural na Pós-modernidade. Tradução: Tomaz Tadeu da Silva; Guacira Lopes Louro. $11^{a}$ edição. Rio de Janeiro: Editora D\&P, 2006.

HORN, M. G. S. Sabores, Cores, Sons, aromas: a organização dos Espaços na Educação Infantil. Porto Alegre: Artmed, 2004.

PACÍFICO, J. M. Políticas públicas para a Educação Infantil em Porto Velho/RO (1999/2008). Araraquara. 2010. 358 p. Tese (Doutorado em Educação Escolar). Universidade Estadual Paulista, Faculdade de Ciências e Letras, Campus de Araraquara.

RINALDI, C. A Pedagogia da Escuta. In.: EDWARDS, C.; GANDINI, L.; FORMAN, G. As Cem Linguagens da criança. Porto Alegre: Penso, 2016. V. 2, 399 p.

SALLES, F.; FARIA, V. L. B. Currículo na Educação Infantil: diálogo com demais elementos da proposta pedagógica. $2^{a}$ edição. São Paulo: Ática, 2012.

SACRISTÁN, J. G. Poderes instáveis em educação. Porto Alegre: ARTMED SUl, 1999.

SARMENTO, M. J. Sociologia da Infância: Correntes e Confluências. In.: 
SARMENTO, M. J.; GOUVEIA, M. C. S. Estudos da Infância: Educação e Práticas Sociais. Petrópolis: Editora: Vozes, 2008. 277 p.

SARMENTO, M. J. As Culturas da Infância nas Encruzilhadas da Segunda Modernidade. In: SARMENTO, M. J.; CERISARA, A. B. Crianças e Miúdos: Perspectivas sociológicas da infância e educação. Portugal: Asa editores, S.A., 2004. 256 p. (Coleção em foco).

SANTILI, J. Socioambientalismo e novos direitos. São Paulo: Peirópolis, 2005.

SILVA, A. P. S.; PASUCH, J.; SILVA, J. B. Educação Infantil do campo. São Paulo: Cortez, 2012. 271 p. (Coleção Docência em Formação).

SILVA, I. O.; SILVA, A. P. S.; MARTINS, A. A. Infâncias no e do campo: como as crianças vivem, brincam, estudam e compartilham experiências. In: ARAUJO, M. O. Infâncias do Campo. 4. ed. Belo Horizonte: Autêntica, 2013. Cap. 2. p. 41-57. (Caminhos da Educação do Campo).

PASUCH, J.; SILVA, A. P. S. Orientações Curriculares para a Educação Infantil do Campo. Anais I Seminário Nacional: Currículo em Movimento Perspectivas Atuais. Belo Horizonte, 2010.

SILVA, H. M.; MACHADO; E. M. A.; PACÍFICO, J. M. O Protagonismo do Coordenador Pedagógico na Formação Docente: Experiência na Educação Infantil em Ji-Paraná-RO. Revista Exitus, Santarém/Pará, v. 08. n.2, p. 111 - 136. Maio/agosto, 2018.

SOUZA, M. F. G. Para além de coelhos e corações: reflexões sobre a prática pedagógica do educador infantil. Linhas críticas, v. 6, n.10. jan. a jun./2000.

SILVA, I. O.; SILVA, A. P. S.; MARTINS, A. A. Infâncias no e do campo: como as Crianças Vivem, brincam, estudam e compartilham experiências? In.: SILVA, I. O.; SILVA, A. P. S.; MARTINS, A. A. Infâncias do Campo. 4. ed. Belo Horizonte: Autêntica, 2013. 284 p. (Caminhos da Educação do Campo).

Recebido em: 12 de setembro de 2021. Aprovado em: 02 de dezembro de 2021.

Publicado em: 07 de janeiro de 2022. 